\title{
NORMA REGULAMENTADORA 12 EM UMA UNIDADE DE PRODUÇÃO MINERAL ${ }^{1}$ REGULATORY STANDARD 12 IN A MINERAL PRODUCTION UNIT

\author{
Juliano Bitencourt Bissacotti² e Luciano Schuastz Aupt ${ }^{3}$
}

\section{RESUMO}

Esta pesquisa situa-se no contexto das normas regulamentadoras obrigatórias a serem adotadas no Brasil por empresas que têm empregados regidos pela Consolidação das Leis do Trabalho (CLT). Por meio de observação participante e pesquisa bibliográfica e documental, analisa-se a aplicabilidade da Norma Regulamentadora $\mathrm{n}^{\mathrm{o}} 12$ (NR-12) em uma unidade de produção mineral, localizada no município de Santa Maria, no estado do Rio Grande do Sul, na região sul do Brasil. Chama-se a atenção para os perigos e riscos à saúde e à integridade física dos trabalhadores que operam o britador primário e a esteira transportadora. Enfatiza-se a importância da utilização de itens de segurança no trabalho, bem como treinamento e capacitação voltados à operação, à manutenção e ao uso de Equipamento de Proteção Individual (EPI). Verificou-se, como resultado do estudo de caso, ausência de dispositivos de segurança, indicados pela NR-12, e, a partir disso, apresentou-se uma proposta de adequação, com o objetivo de identificar os perigos e riscos presentes nos equipamentos, como falta de proteções fixas e dispositivos de segurança, e propor medidas de adequação, utilizando a metodologia Hazard Rating Number (HRN), que se mostrou efetiva na redução dos riscos extremos e muito altos para uma condição de risco aceitável.

Palavras-chave: britador primário, esteira transportadora, riscos, EPI, NR-12.

\section{ABSTRACT}

The research work is in the context of mandatory regulatory standards to be adopted in Brazil by companies that have employees governed by the Labor Laws' Consolidation (LLC). Through, participant observation and bibliographic and documentary research, the aim is to analyze the applicability of Regulatory Standard 12 (RS-12) in a mineral production unit, located in the municipality of Santa Maria, in the state of Rio Grande do Sul, in the region southern Brazil. Attention is drawn to the dangers and risks to the health and physical integrity of the workers who operate the primary crusher and the conveyor belt. The importance of using safety items at work, as well as training and qualification, focused on the operation, maintenance and use of Personal Protective Equipment (PPE) is emphasized. In the case study, it verifies the absence of safety devices, indicated by the Regulatory Norm $12(R N-12)$ and tries to present a suitability proposal, which proved to be effective in reducing extreme and very high risks to an acceptable risk condition.

Keywords: conveyor belt, primary crusher, risk, ppe, rn-12.

1 Trabalho de Conclusão de Curso - Artigo

2 Aluno do curso de Especialização em Engenharia de Segurança do Trabalho - Universidade Franciscana. E-mail: julianobissacotti@hotmail.com ou julianobissacotti2021@gmail.com

3 Orientador - Universidade Franciscana. E-mail: lucianoaupt@ufrgs.broulsaupt@gmail.com 


\section{INTRODUÇÃO}

O Brasil possui um dos maiores patrimônios minerais do mundo, e a mineração é um elo fundamental da cadeia produtiva brasileira para que o desenvolvimento nacional ocorra (PORTAL DA MINERAÇÃO, 2020).Conquistou posição de destaque no cenário global, tanto em reservas como em produção mineral. No ano de 2019, o valor da produção mineral brasileira foi de US\$ 38 bilhões, o que representou cerca de $16,8 \%$ do PIB Industrial do país (INSTITUTO BRASILEIRO DE MINERAÇÃO, 2020).

A mineração é um setor importante para o país e pode causar impactos relevantes ao trabalhador, oferecendo riscos à saúde e à segurança humana quando executado de forma inadequada, podendo, inclusive, causar óbitos. Assim, faz-se necessária a identificação dos riscos ambientais e perigos causados pela atividade da mineração, a fim de proteger a saúde do trabalhador, o qual está exposto, durante o processo, a riscos químicos, causados pelas poeiras minerais; riscos físicos, como o ruído, vibração e radiação não ionizante; riscos ergonômicos provenientes da operação, como postura inadequada. Esses riscos são extremamente prejudiciais se expostos sem os devidos cuidados, pois afetam diretamente o trabalhador, e as principais doenças que podem ser causadas são: perda auditiva e doenças pulmonares (BRASIL, 1978a).

Conforme Adams e Thompson (2002), existe uma formulação de três categorias genéricas para a identificação de riscos: os percebidos diretamente, os percebidos por meio da ciência e os riscos virtuais. Os primeiros são percebidos pela generalidade das pessoas (normalmente designados como saberes leigos); os segundos só são percebidos por meio de métodos científicos, é algo restrito aos não cientistas (pelo menos até a sua divulgação); os últimos são riscos sobre os quais não existe consenso sobre a sua verdadeira existência, mas, inquestionavelmente, os dois primeiros são importantes para a gestão do risco. Para tanto, é necessário conhecer e aplicar as normas de forma correta no que se refere à higiene e segurança do trabalho.

De acordo com a Norma Regulamentadora no 22 (NR-22), "Segurança e saúde ocupacional na mineração", alguns dos riscos encontrados no ambiente de trabalho da mineração são a poeira de sílica e os ruídos de máquinas, além da falta de proteções em partes móveis dos equipamentos, todos muito prejudiciais à segurança e à saúde do trabalhador. Outro fator que esses riscos, quando traduzidos em acidentes, acabam causando é a redução da produção, pela interrupção do trabalho devido a acidentes de trabalho, o que gera custos elevados para as empresas (BRASIL, 1978a). A Norma Regulamentadora n 17 (NR-17), "Ergonomia",visa estabelecer parâmetros que permitam a adaptação das condições de trabalho às características psicofisiológicas dos trabalhadores, de modo a proporcionar o máximo de conforto, segurança e desempenho eficiente durante a atividade (BRASIL, 1978f).

Essas atitudes demonstram a valorização do ser humano, que, bem cuidado e protegido, contribuirá de forma significativa para a empresa à qual estiver prestando serviços. 
A segurança do trabalho, desde que seja implementada seguindo as normas vigentes, é um tema de extrema importância que deve ser valorizado pelas empresas e seus colaboradores, uma vez que atua na identificação e prevenção contra riscos e na minimização de acidentes e doenças ocupacionais (BRASIL, 1978e).

O Ministério do Trabalho e Previdência Social (MTPS) ${ }^{4}$ criou normas regulamentadoras obrigatórias a todo trabalhador regido pela Consolidação das Leis Trabalhistas (CLT), com o objetivo de prevenir acidentes e doenças relacionadas ao trabalho. São 37 Normas Regulamentadoras (NR) criadas para proteger a saúde e dar segurança ao trabalhador. Ente estas, duas foram revogadas: a Norma Regulamentadora nº2 (NR-02), “Inspeção prévia” (BRASIL, 1978b), e a Norma Regulamentadora $n^{\circ} 27$ (NR-27), "Registro profissional do técnico de segurança do trabalho" (BRASIL, 1978c). Algumas são aplicáveis ao tema desta pesquisa, a exemplo da Norma Regulamentadora $\mathrm{n}^{\circ} 01$ (NR-01), "Disposições gerais e gerenciamento de riscos ocupacionais", que apresenta informações quanto às competências de cada órgão relacionado à segurança e à saúde no trabalho, as responsabilidades de empregadores e empregados (BRASIL, 1978d); a NR-12, que trata da “Segurança no trabalho em máquinas e equipamentos", a NR-22, "Segurança e saúde ocupacional na mineração" (BRASIL, 1978a).

A política de saúde e segurança do trabalho (SST) instituída por meio das NRs, pelo Ministério da Economia, contribui para o estabelecimento das mudanças e melhorias necessárias, já que promove maior comprometimento das gerências das empresas com a segurança e a saúde do trabalhador. A Norma Regulamentadora $n^{\circ} 12$ (NR-12) (BRASIL, 1978f) determina as medidas necessárias para resguardar a saúde e a integridade física dos trabalhadores e estabelece os requisitos mínimos para a prevenção de acidentes e doenças do trabalho, nas fases de projeto e de utilização de máquinas e equipamentos. Para o atendimento da NR-12, é necessário conhecer os processos de trabalho, os espaços físicos onde estes ocorrem, os tipos de trabalho a serem realizados, os riscos e perigos existentes em cada atividade. Por sua vez, a NR-22 determina a elaboração do Programa de Gerenciamento de Riscos (PGR), obrigando as empresas do setor de mineração a agirem de modo preventivo, garantindo a segurança e a saúde de todos os envolvidos no processo(BRASIL, 1978a).

Conforme a Norma Regulamentadora no 09 (NR-09), "Programa de prevenção de riscos ambientais", existem diferentes medidas que podem ser implementadas para controlar a exposição dos trabalhadores, nos locais de trabalho, ao risco de acidente e/ou doenças ocupacionais. Essas medidas são importantes, considerando o método de controle mais eficaz. Segundo a NR-01, devem ser adotadas as seguintes ações na prevenção de acidentes e doenças ocupacionais existentes no local: eliminação dos agentes de risco, minimização e controle dos fatores de risco com medidas de proteção coletiva e ou administrativa e a adoção de medidas de proteção individual. Ações de treinamentos aos

4 O Ministério do Trabalho foi extinto pelo governo de Jair Bolsonaro, em 2019, tendo suas atribuições atualmente divididas entre os ministérios da Economia, Cidadania e Justiça e Segurança Pública. 
trabalhadores, proteções nas máquinas e, caso não seja possível eliminar, minimizar ou controlar os riscos presentes nas máquinas e equipamentos, deve-se fazer uso de EPIs.

Seguindo essas perspectivas, neste trabalho, tem-se por objetivo, analisar a aplicabilidade da NR-12 em uma unidade de produção mineral, no sul do Brasil. De maneira específica, busca-se: a) informar sobre riscos à saúde e integridade física dos trabalhadores que operam equipamentos e máquinas mineradoras; b) enfatizar itens de segurança no trabalho e a importância do treinamento e da capacitação voltados à operação, à manutenção e ao uso de Equipamento de Proteção Individuais (EPIs); c) identificar os dispositivos de segurança, indicados pela NR-12, durante atividade de operação do britador primário e da esteira transportadora.

Após análise, evidencia-se que não foi possível satisfazer plenamente as exigências da NR-12 e diante disso, apresenta-se uma proposta de adequação.

\section{METODOLOGIA}

De acordo com Yin (2015), o estudo de caso apresenta seis evidências: documentação, registros em arquivos, emtrevistas, observações diretas, observação participante e artefatos físicos. Neste estudo de caso, combinou-se o modo exploratório e explicativo, pesquisa documental e bibliográfica. Fez-se uso das análises qualitativa e quantitativa de dados, à luz do Hazard Rating Number (HRN), de acordo com ABNT NBR 14153 (ASSOCIAÇÃO BRASILEIRA DE NORMAS TÉCNICAS, 2013). Além disso, fez-se a análise de dados primários e secundários, também de acordo com a NBR 14153.

A observação participante se deu enquanto o autor teve acesso à mineradora, localizada no município de Santa Maria, no estado do Rio Grande do Sul, no período de janeiro a setembro de 2020, na condição de pesquisador e engenheiro ambiental contratado pela referida empresa mineradora.

\section{PROCEDIMENTO METODOLÓGICO}

A definição da categoria de segurança das máquinas é realizada conforme ABNT NBR 14153, de 2013. Verificou-se, no local, o funcionamento das máquinas e dos equipamentos, as etapas da operação, a identificação e análise dos perigos, as estimativas e a avaliação qualitativa dos riscos (sem e com segurança) por meio da verificação de dispositivos de segurança existentes para redução dos riscos, pontuação, indicação de sinalizações para alerta dos riscos, elaboração de Procedimentos de Trabalho e Segurança, produção de Manual Técnico. Desse modo, foi utilizada a metodologia Hazard Rating Number (HRN) (Número de Classificação do Perigo), conforme a equação 1. Esse método classifica um risco em aceitável ou não e tem grande eficácia, pois, a partir de um risco identificado, relacionado ao perigo considerado, tem-se uma função da gravidade do dano com a probabilidade de ocorrência desse mesmo dano para um dado número de trabalhadores expostos. 


$$
H R N=L O . F E . D P H . N P
$$

Sendo:

LO - Probabilidade de ocorrência;

FE - Frequência de exposições;

DPH - Gravidade de possível lesão;

NP - Número de pessoas expostas.

Na avaliação do risco de segurança, conforme NBR14153, de 2013, estabeleceu-se a seleção da categoria de segurança, conforme figura 1.

Para a Severidade do Ferimento, tem-se o valor S, em que S1 é leve (normalmente reversível) e S2 é grave (normalmente irreversível). Com relação ao índice F, que representa a frequência e o tempo de exposição, F1 é Raro (relativamente frequente e/ou baixo tempo de exposição) e F2 para frequente (até contínuo e ou tempo de exposição longo). Já a possibilidade de evitar o perigo representa-se pelo índice P: P1 para possível (sob condições específicas) e o P2 para quase (nunca possível).

Figura 1 - Categoria de segurança.

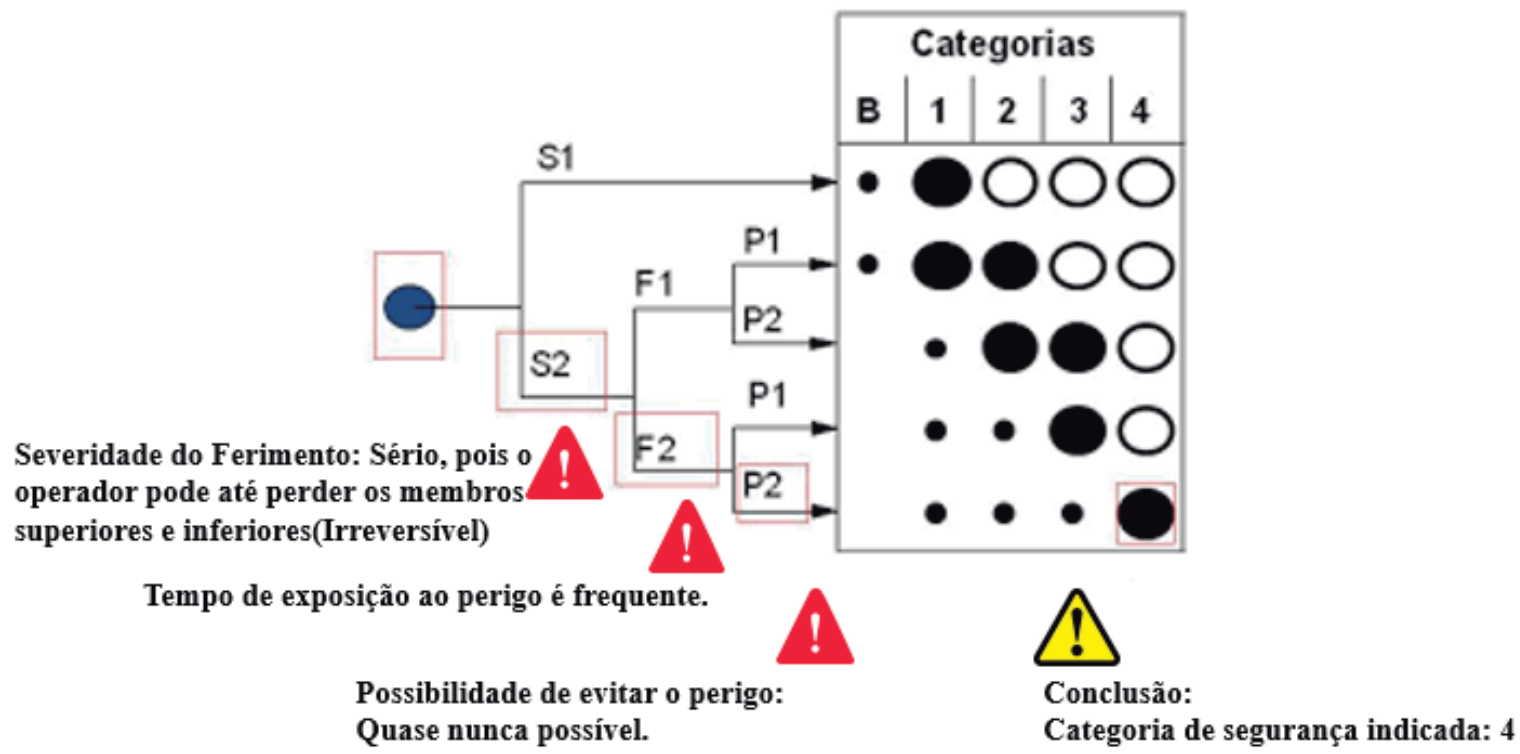

Fonte: Adaptado de ABNT NBR 14153 (2013).

As seleções possíveis de categoria são: para a categoria preferencial recomendada (simbolizada por ), para as medidas que podem ser superdimensionadas para o risco relevante (simbolizada por $\bigcirc$ ) e a categoria que requer medidas adicionais, pois o sistema não está seguro (simbolizada por $\bullet$ ).

Os parâmetros utilizados, assim como as variáveis que cada um representa, têm descritos e quantificados seus valores de referência na tabela 1. 
Tabela 1 - Parâmetros e variáveis do Método Hazard Rating Number.

\begin{tabular}{clcl}
\hline \multicolumn{4}{c}{ Parâmetros e variáveis do Método Hazard Rating Number } \\
\hline \multicolumn{1}{c}{ 1 } & Probabilidade de Ocorrência (LO) & 2 & - Frequência de Exposições (FE) \\
\hline 0,3 & Quase impossível & 0,5 & Atualmente \\
\hline 1 & Altamente improvável & 1 & Mensalmente \\
\hline 1,5 & Improvável & 1,5 & Semanalmente \\
\hline 2 & Possível & 2,5 & Diariamente \\
\hline 5 & Alguma chance & 4 & Em termos de hora \\
\hline 8 & Provável & 5 & Constantemente \\
\hline 10 & Muito provável & & \\
\hline 15 & Certo & 4 - Número de pessoas expostas (NP) \\
\hline 3 & Gravidade de possível lesão (DPH) & 1 & $1-2$ pessoas \\
\hline 0,1 & Arranhão / Contusão leve & 2 & $3-7$ pessoas \\
\hline 0,5 & Dilaceração / Doenças moderadas & 4 & $8-15$ pessoas \\
\hline 2 & Fratura / Enfermidade leve & 8 & $16-50$ pessoas \\
\hline 4 & Fratura / Enfermidade grave & 12 & Mais que 50 \\
\hline 6 & Perda de um membro / olho & & \\
\hline 10 & Perda de dois membros / olhos & Fonte: Adaptado de ABNT NBR 14153 (2013). \\
\hline 15 & Fatalidade & & \\
\hline & & & \\
\hline
\end{tabular}

Os valores do HRN com a classificação do risco e sua descrição estão representados na tabela 2.

Tabela 2 - Valores do HRN e a classificação do risco.

\begin{tabular}{cc}
\hline HRN & RISCO \\
\hline $0<1$ & Aceitável \\
$1<5$ & Muito Baixo \\
\hline $5<10$ & Baixo \\
$10<50$ & Significante \\
$50<100$ & Alto \\
\hline $100<500$ & Muito Alto \\
$500<1000$ & Extremo \\
\hline$>1000$ & Inaceitável \\
\hline Fonte: Adaptado de ABNT NBR 14153 (2013).
\end{tabular}

\section{RESULTADOS E DISCUSSÃO}

\section{APLICAÇÃO DA METODOLOGIA HAZARD RATING NUMBER (HRN)}

\section{Verificação de dispositivos de segurança existentes}

$\mathrm{Na}$ tabela 3, são apresentadas as verificações de dispositivos de segurança existentes no britador primário: Botão/Cabo emergência; Painel comandos 25 v máx.; Rearme (Reset) manual; Dispositivos de segurança; Proteções mecânicas móveis Inter travadas; Proteções mecânicas fixas; 
Aterramento; Escada de acesso; Plataforma de trabalho, Chave seccionadora para Lock out-tag out; Check list de inspeção por turno antes de iniciar a atividade; Operador treinado (capacitado) na NR-12; Operador treinado (capacitado) na operação de trabalho com evidência; Manutenção preventiva/corretiva em dispositivos de segurança e laudo final de conformidade com a NR-12. No total, são 15 itens de segurança, entre os quais três itens têm e atendem a NR-12: "Plataforma de trabalho"; Operador treinado (capacitado) na NR-12; Operador treinado (capacitado) na operação de trabalho com evidência. Três itens têm mas não atendem a NR-12: Botão/Cabo emergência; Painel comandos 25 v máx.; Escada de acesso. Nove itens não têm mas necessitam: Rearme (Reset) manual; Dispositivos de segurança; Proteções mecânicas móveis Inter travadas; Proteções mecânicas fixas; Aterramento; Chave seccionadora para Lock out-tag out; Check list de inspeção por turno antes de iniciar a atividade; Manutenção preventiva/corretiva em dispositivos de segurança e Laudo final de conformidade com a NR-12. Observou-se a não evidência de laudo de aterramento da máquina, bem como a ausência de rodapé de $20 \mathrm{~cm}$ de altura.

Tabela 3 - Dispositivos de segurança existentes.

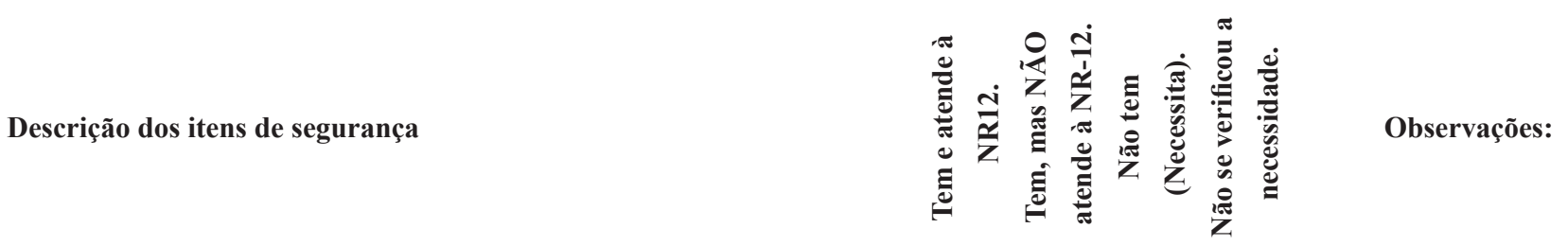

\begin{tabular}{|c|c|c|c|c|}
\hline 1 - Botão/Cabo emergência & & $\mathrm{X}$ & & \\
\hline 2 - Painel comandos em $25 \mathrm{v}$ máx & & $\mathrm{X}$ & & \\
\hline 3 - Rearme (Reset) manual & & & $\mathrm{X}$ & \\
\hline 4 - Dispositivos de segurança & & & $\mathrm{X}$ & \\
\hline 5 - Proteções mecânicas móveis intertravadas & & & $\mathrm{X}$ & \\
\hline 6 - Proteções mecânicas fixas & & & $\mathrm{X}$ & \\
\hline 7 - Aterramento & & & $\mathrm{X}$ & $\begin{array}{l}\text { Não evidenciado laudo de } \\
\text { aterramento da máquina }\end{array}$ \\
\hline 8 - Escada de acesso & & $\mathrm{X}$ & & $\begin{array}{l}\text { Falta rodapé de } \\
20 \mathrm{~cm} \text { de altura }\end{array}$ \\
\hline 9 - Plataforma de trabalho & $\mathrm{X}$ & & & \\
\hline 10 - Chave Seccionadora para Lock out - Tag out & & & $\mathrm{X}$ & \\
\hline 11 - Check List de inspeção por turno antes de iniciar a atividade & & & $\mathrm{X}$ & \\
\hline 12 - Operador treinado (capacitado) na NR-12 & $\mathrm{X}$ & & & \\
\hline 13 - Operador treinado (capacitado) na operação de trabalho com evidência & $\mathrm{X}$ & & & \\
\hline 14 - Manutenção preventiva/corretiva em dispositivo de segurança. & & & $\mathrm{X}$ & \\
\hline 15 - Laudo final de conformidade com a NR-12. & & & $\mathrm{X}$ & \\
\hline
\end{tabular}

Fonte: Adaptado de ABNT NBR 14153 (2013).

A tabela 3 foi decisiva para a visualização dos itens de segurança. A partir dessa tabela, é possível aplicar a metodologia HAZARD RATING NUMBER (HRN), que se mostrou eficaz na redução do risco extremo e risco muito alto para uma situação aceitável, conforme descrito a seguir. 


\section{Definição das categorias de instalação de segurança conforme NBR 14153 (2013)}

\section{Britador Primário}

A descrição da categoria de segurança do britador primário, conforme figura 1 , ficou identificada na categoria 4. Conforme as figuras 2 e 3, pode-se identificar o perigo, o contato com as partes móveis sem proteção e o risco de queda quando o operador está desembuchando as pedras (Figura 3). A proteção existente é a casa de comandos. Quando o operador sai desta, existe a possibilidade de contato do seu corpo com as partes móveis da máquina em movimento, como polias, correias e mandíbulas.

Figura 2 - Casa e britador primário.

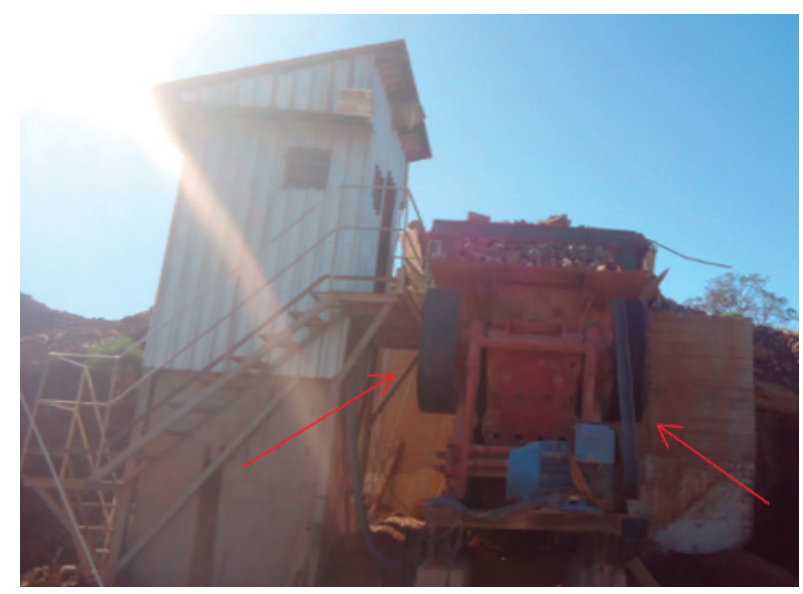

Figura 3 - Britador primário: Vista superior.

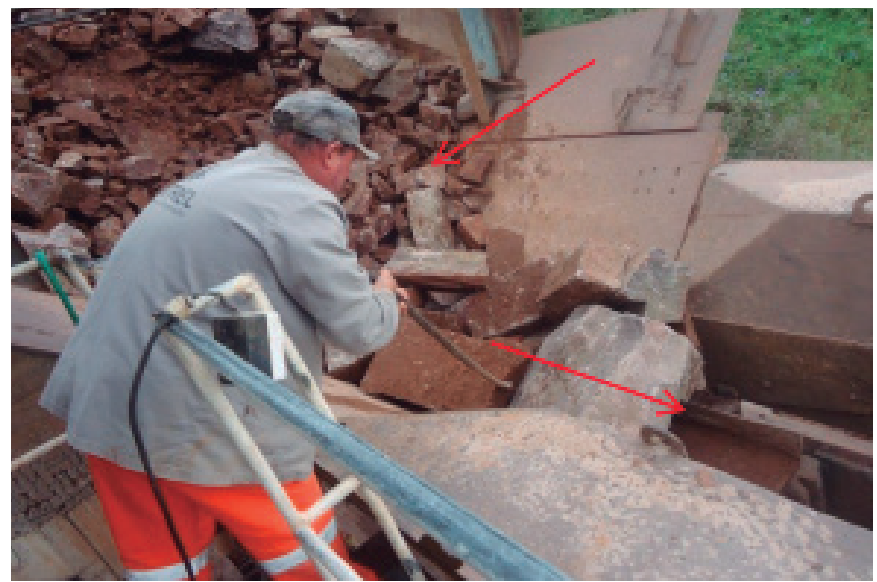

Fonte: Autor (2020).

A partir dessa verificação, as zonas de perigo devem ter sistemas de segurança caracterizados por proteções fixas e dispositivos de segurança interligados que garantam a saúde e a integridade física dos trabalhadores, conforme as figuras 2 e 3.

Aplicando o sistema de segurança recomendado pela metodologia, conforme equação 1 e tabelas 1 e 2, em que, $\mathrm{LO}=10, \mathrm{FE}=5, \mathrm{DPH}=15$ e $\mathrm{NP}=1$, chegou-se ao valor de $\mathrm{HRN}=750$, o que torna o risco extremo.

Com o resultado obtido e a aplicação da NBR 14153 (2013), foi realizada a colocação de proteções fixas nas partes móveis do britador primário (Figura 4) e onde havia risco de queda do operador. Além disso, foram colocadas chaves de segurança monitoradas por interface de segurança em tampa na boca do britador, conforme figura 5 .

Foram instalados dispositivos de parada de emergência, conforme figura 5, em local de fácil acesso e visualização pelos operadores e por outras pessoas, um em cada lado do britador no nível inferior, acessível do chão e um dispositivo próximo à boca do britador. Os dispositivos instalados são monitorados por interface de segurança e exigem rearme ou reset manual após a correção do evento que motivou o acionamento da parada de emergência. 
Aplicando o método após as correções na segurança da máquina, conforme equação 1 e tabelas 1 e 2, em que $\mathrm{LO}=1, \mathrm{FE}=5, \mathrm{DPH}=0,1$ e $\mathrm{NP}=1$, chegou-se ao $\mathrm{HRN}$ com valor de 0,5 , o que torna o risco aceitável.

Figura 4 - Britador Primário: Vista Frontal.

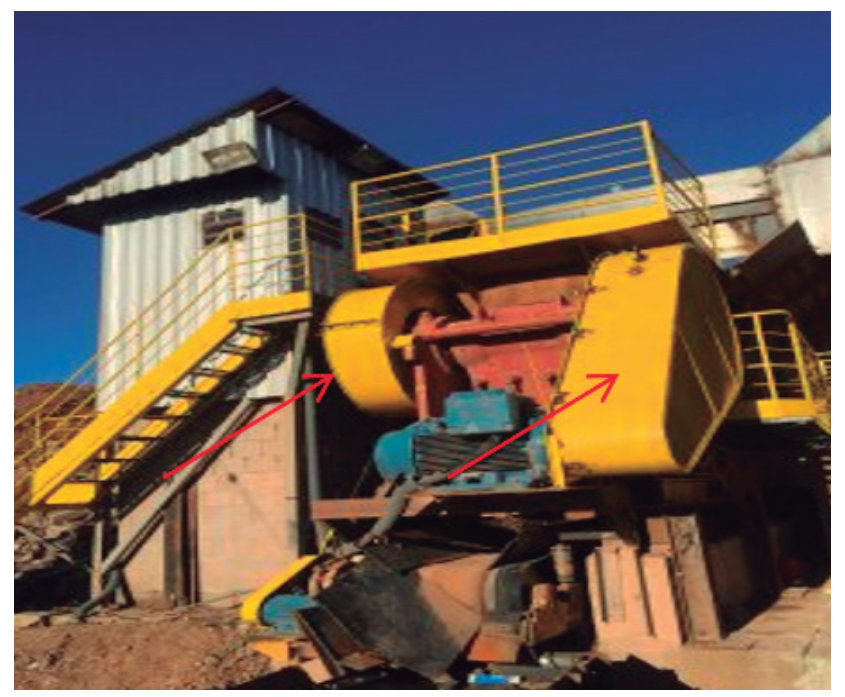

Figura 5 - Britador Primário: Vista Superior.

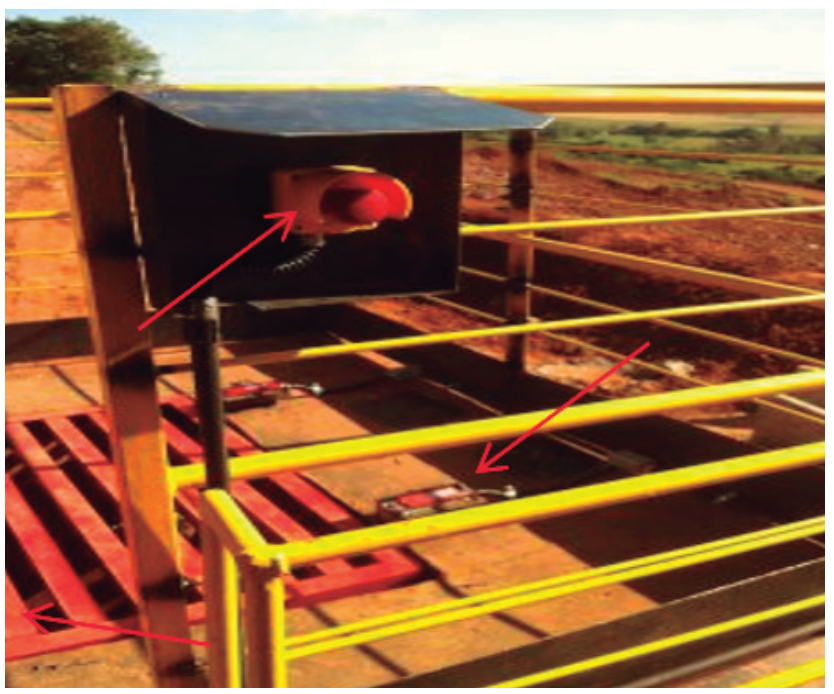

Fonte: Autor (2020).

Esteira Transportadora

A descrição da categoria de segurança da esteira transportadora da figura 6, aplicando o sistema de segurança recomendado HRN, conforme equação 1 e tabelas 1 e 2, em que, $\mathrm{LO}=10, \mathrm{FE}=2,5$, $\mathrm{DPH}=4$ e NP=2, chegou-se a um índice de 200, o que torna o risco muito alto. Esse valor descreve o que é identificado por meio do perigo nas partes móveis sem proteção. Esses parâmetros indicam a seleção da categoria 4 (quatro).

Figura 6 - Esteira transportadora.

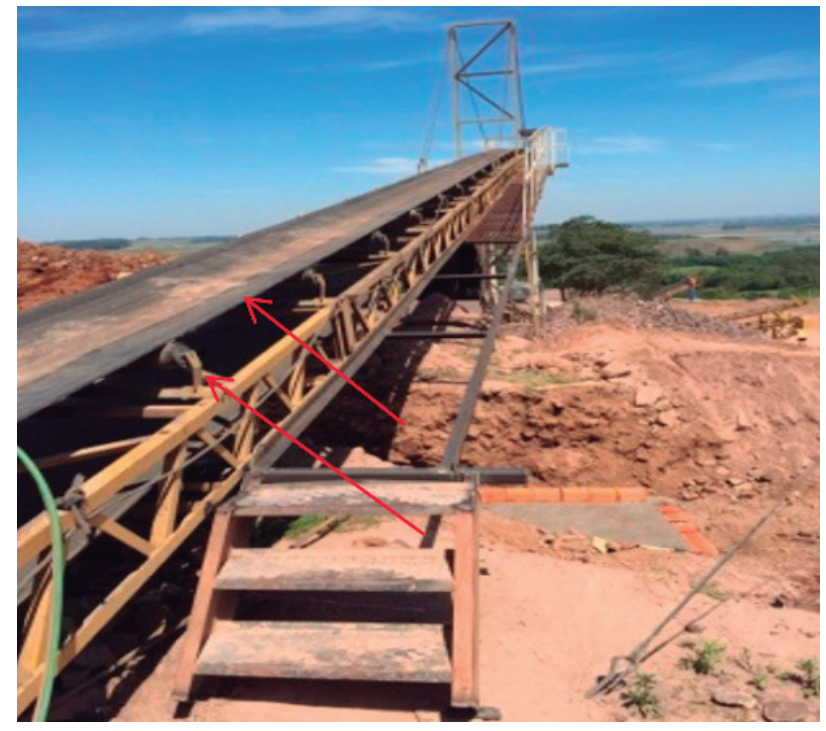

Fonte: Autor (2020). 
As zonas de perigo devem ter sistema de segurança caracterizado por proteções fixas que garantam a proteção à saúde e à integridade física dos trabalhadores. Para isso, foi colocada uma passarela (Figura 7 e 8) com guarda corpo em ambos os lados, protegendo contra quedas e o contato com as partes móveis, além de um dispositivo de parada de emergência em local de fácil acesso e visualização pelos colaboradores e por outras pessoas.

Aplicando o sistema de segurança recomendado HRN, conforme equação 1 e tabelas 1 e 2, em que $\mathrm{LO}=1, \mathrm{FE}=2,5, \mathrm{DPH}=0,1$ e $\mathrm{NP}=2$, chegou-se ao valor de 0,5 , o que torna o risco aceitável.

Figura 7 - Esteira Transportadora.

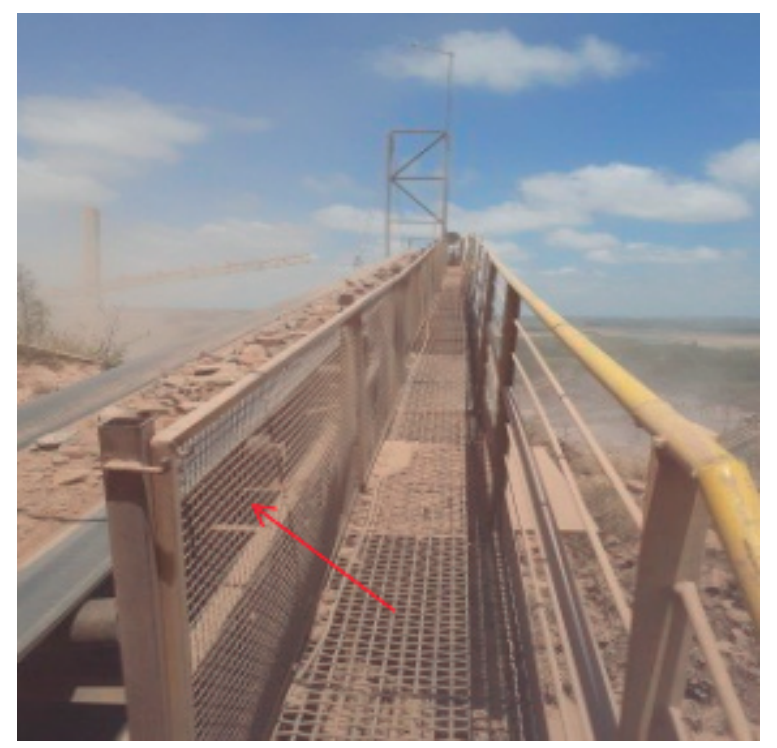

Figura 8 - Esteira Transportadora.

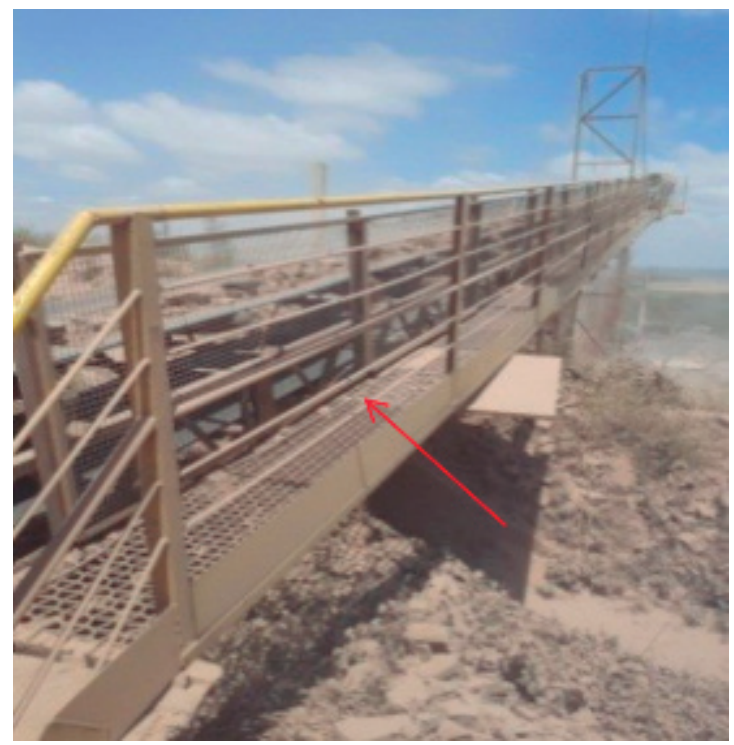

Fonte: Autor (2020).

\section{Painel Controle do Britador}

No que se refere à categoria de segurança do painel de controle, conforme as figuras 9 e 10 , identificaram-se perigos nas partes vivas sob condições de falha ou curto-circuito, de acordo com a ISO 12100 (ASSOCIAÇÃO BRASILEIRA DE NORMAS TÉCNICAS, 2013b), e a falta de conexão para aterramento. Houve também a identificação do risco e proteção à fiação viva. Esses parâmetros indicam a seleção da categoria 4 (quatro).

Aplicando o sistema de segurança recomendado HRN, conforme equação 1 e tabelas 1 e 2, em que $\mathrm{LO}=10, \mathrm{FE}=4, \mathrm{DPH}=15$ e NP=1, chegou-se ao valor de 600 , o que torna o risco extremo. 
Figura 9 - Painel de controle 1.

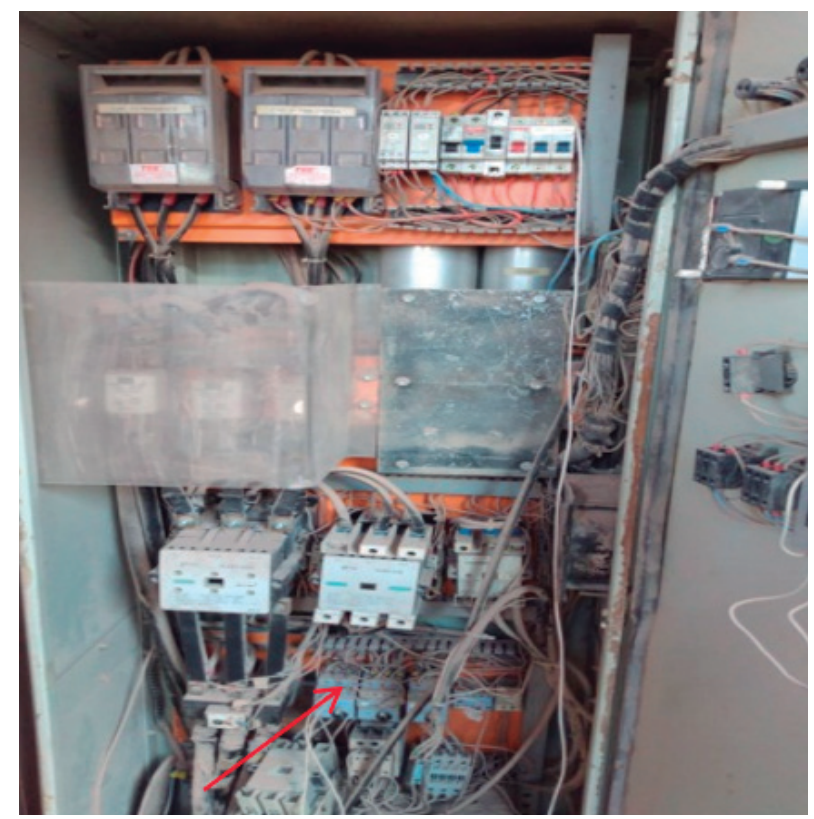

Figura 10 - Painel de controle 2.

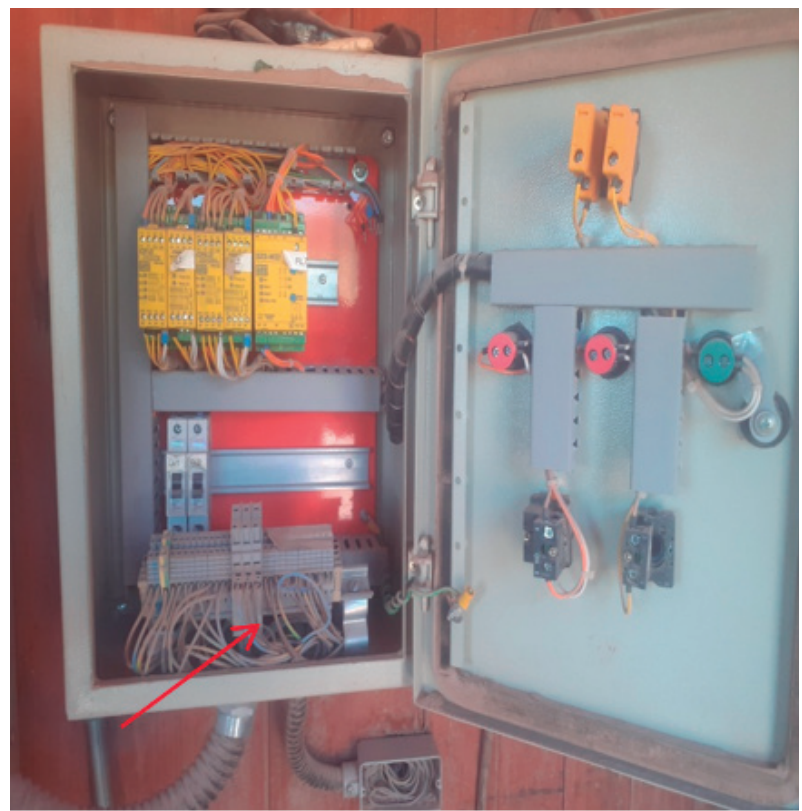

Fonte: Autor (2020).

Verificando as zonas de perigo, deve-se instalar sistema que possibilite o isolamento e a descarga da energia elétrica dos quadros de comando, isolamento das partes com risco de choque elétrico, painel com 25 Volts em CA (vinte e cinco volts em corrente alternada) e 60 Volts em CC (sessenta volts em corrente contínua), ter chave geral que corte a energia elétrica de toda a máquina e permita 0 bloqueio, disjuntor como proteção contra sobre corrente, painel chaveado e com aterramento e medição, atendendo à regulamentação estabelecida na Norma Regulamentadora nº 10 (NR-10) (BRASIL, 1978g), "Segurança em instalações e serviços em eletricidade", complementando com laudo de aterramento e sinalização de perigo de choque.

Aplicando o sistema de segurança recomendado $H R N$, conforme equação 1 e tabelas 1 e 2 , em que $\mathrm{LO}=1,5, \mathrm{FE}=4, \mathrm{DPH}=0,1$ e $\mathrm{NP}=1$, chegou-se ao valor de 0,6 , o que torna o risco aceitável. O sistema de segurança proposto está na figura 11. 
Figura 11 - Painel de controle.

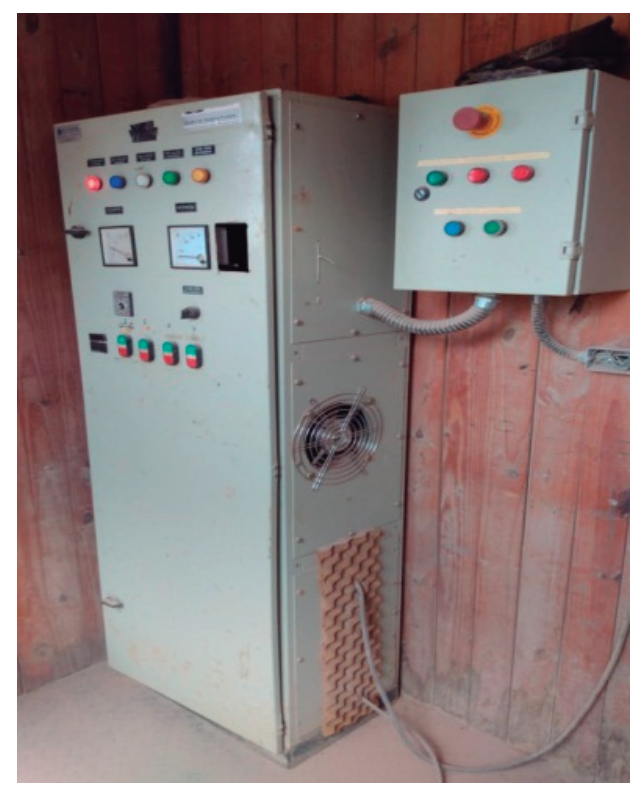

Fonte: Autor (2020).

\section{Poeira e Ruído}

Segue a descrição da categoria de segurança do equipamento, conforme a figura 12 , na qual se identifica o perigo de contato com poeira (pó de sílica) em suspensão e ruído elevado do Britador Primário, os quais indicam a seleção da categoria 4 (quatro). Onde existe a medida de proteção de forma parcial, aplicando o sistema de segurança recomendado pela metodologia conforme equação 1 e tabelas $1 \mathrm{e}$ 2, em que $\mathrm{LO}=15, \mathrm{FE}=5, \mathrm{DPH}=4$ e $\mathrm{NP}=1$, chegou-se ao valor $\mathrm{HRN}=300$, o que torna o risco muito alto.

Figura 12 - Britador Primário.

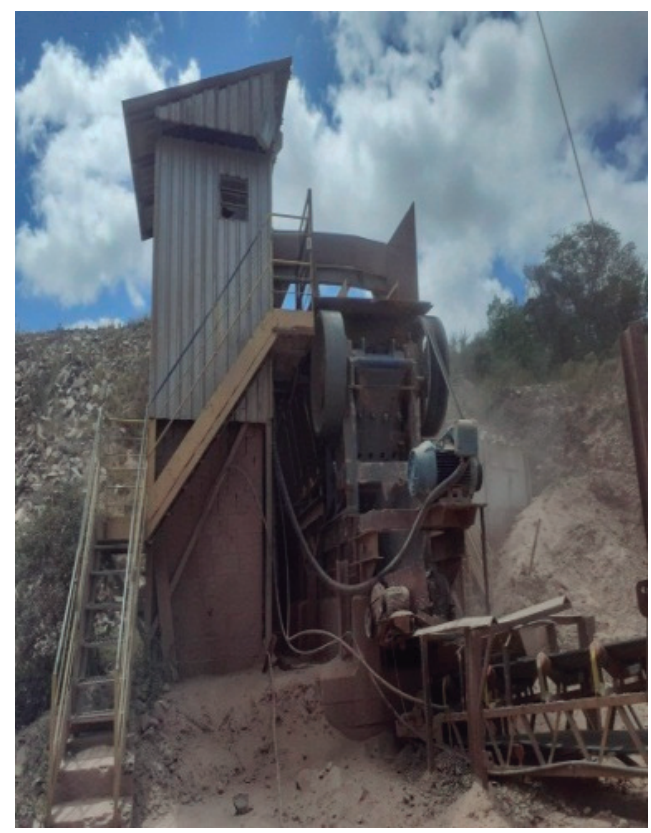

Fonte: Autor (2020). 
Verificando as zonas de perigo, foi implementado um sistema de aspersão de água na fonte para minimizar a concentração de poeira no local (Figura 13) e, para minimizar e ou neutralizar os níveis de poeira e ruído, foi adotado o uso dos seguintes EPIs: óculos de segurança, máscara PFF1 e protetor auricular (Figura 14). Aplicando o sistema de segurança recomendado HRN, conforme equação 1 e tabelas 1 e 2, em que $\mathrm{LO}=1,5, \mathrm{FE}=5, \mathrm{DPH}=0,1$ e $\mathrm{NP}=1$, chegou-se ao valor de 0,75 , o que torna o risco aceitável.

Figura 13 - Sistema de aspersão.

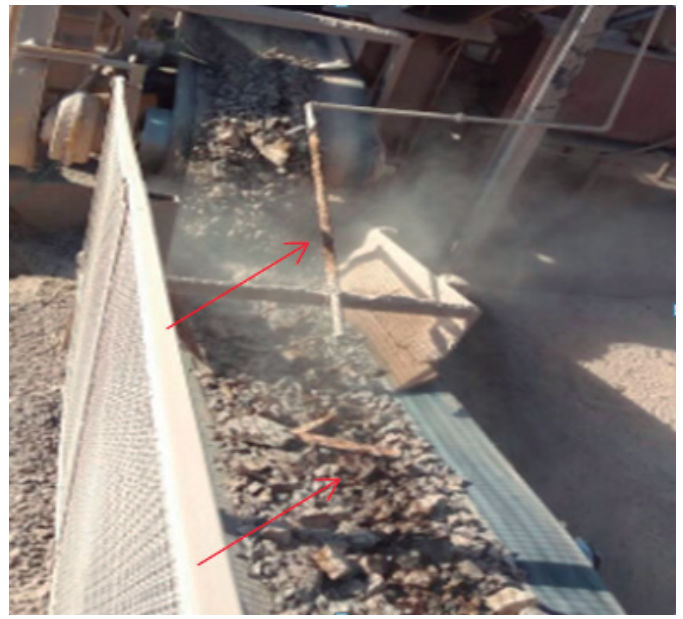

Figura 14 - EPIs.

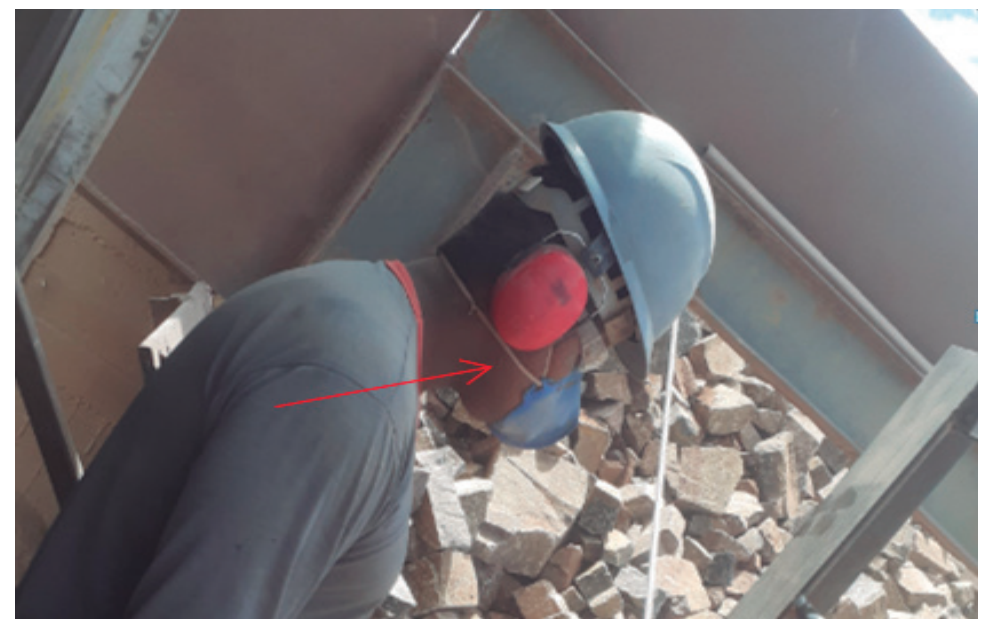

Fonte: Autor (2020).

Indicação de sinalizações para alerta dos riscos

A sinalização de advertência dos perigos e riscos existentes no britador primário necessários à operação do sistema estão contidos nas figuras 15, 16, 17 e 18.

Figura 15 - EPIs obrigatórios.

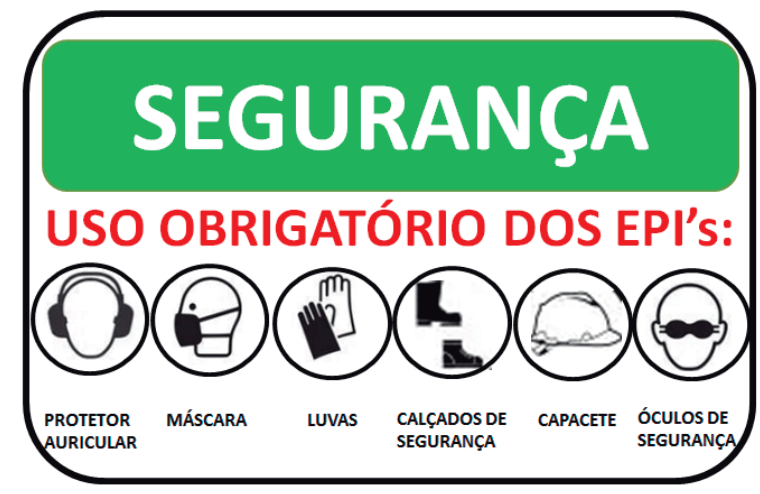

Figura 16 - Perigo choque elétrico.

\section{PERIGO}

CHOQUE
ELÉTRICO 
Figura 17 - Acesso restrito.

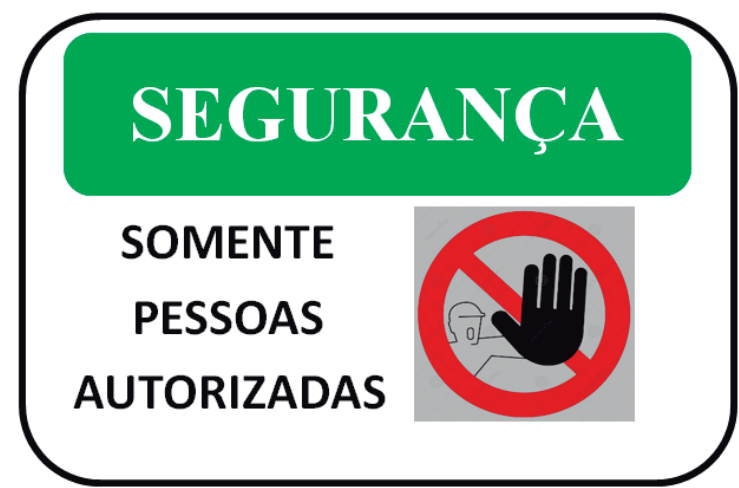

Figura 18 - Operação restrita.

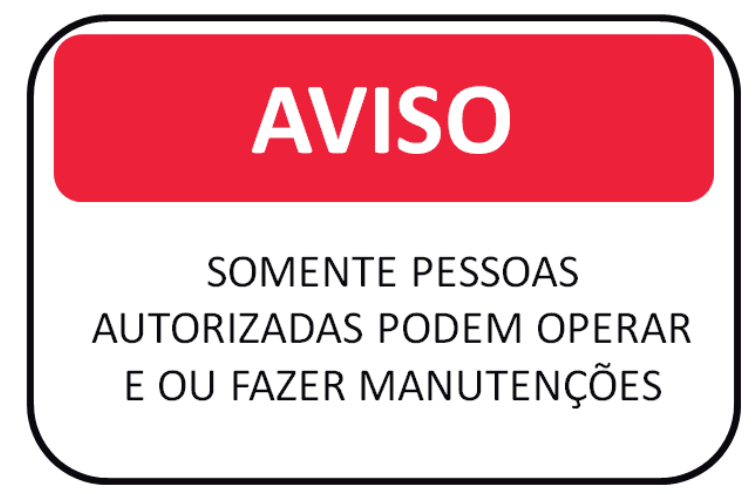

Fonte: Autor (2020). Fonte: Autor (2020).

\section{Procedimentos de Trabalho e Segurança}

Somente operador capacitado e autorizado poderá operar a máquina, e é obrigatório o uso dos seguintes EPIs: capacete, óculos de segurança, protetor auditivo, máscara PFF1, calçado de segurança e luva de segurança. Durante as atividades, é preciso que se mantenha atenção e que se cumpram sempre os avisos de perigo colocados na máquina. As proteções de segurança presentes na máquina nunca devem ser retiradas. Quando o trabalhador identificar que foi retirado por outrem, deverá comunicar imediatamente o setor de segurança do trabalho e a gerência, para que sejam recolocados imediatamente. Os operadores não podem se afastar das áreas de controle das máquinas sob sua responsabilidade quando estas estiverem em funcionamento.

Sempre que necessitar parar a máquina, somente o operador poderá religá-la. Para isso, deve avisar, antes, as pessoas que estão ao seu redor sobre o que vai ser feito e os perigos decorrentes. A manutenção da parte elétrica da máquina e dos equipamentos somente deverá ser feita por profissional habilitado. Considera-se profissional habilitado aquele que tem o curso de eletricista e foi autorizado pela empresa e/ou fabricante. Os reparos, a limpeza, os ajustes e a inspeção somente podem ser executados com a máquina parada e desenergizada, o que significa que não deve haver nenhuma chance de se ligar à máquina, salvo se o movimento for indispensável à sua realização, neste caso, somente profissionais habilitados para a tarefa poderão executá-la. Conforme a NR-10 (BRASIL, 1978g), as empresas que operam em instalações ou equipamentos integrantes do sistema elétrico de potência devem constituir prontuário e acrescentar os documentos a seguir listados: descrição dos procedimentos para emergências e certificações dos equipamentos de proteção coletiva e individual. As proteções da máquina e dos equipamentos só podem ser retiradas para a execução de limpeza, lubrificação, reparo e ajuste com a máquina desligada. Ao fim dos trabalhos, devem ser, obrigatoriamente, recolocados. Nesse caso, devem-se tomar medidas preventivas de bloqueio para que a máquina e/ou equipamento 
não sejam ligados acidentalmente, ou por engano, tarefa que somente profissionais treinados poderão executar, conforme figura 19.

É imprescindível a existência de procedimentos e que estes sejam rigorosamente seguidos, assim como os treinamentos. Além disso, é importante destacar que as medidas de segurança propostas não são únicas, sendo uma das diversas possibilidades de soluções existentes.

Figura 19 - Sistema de bloqueio.

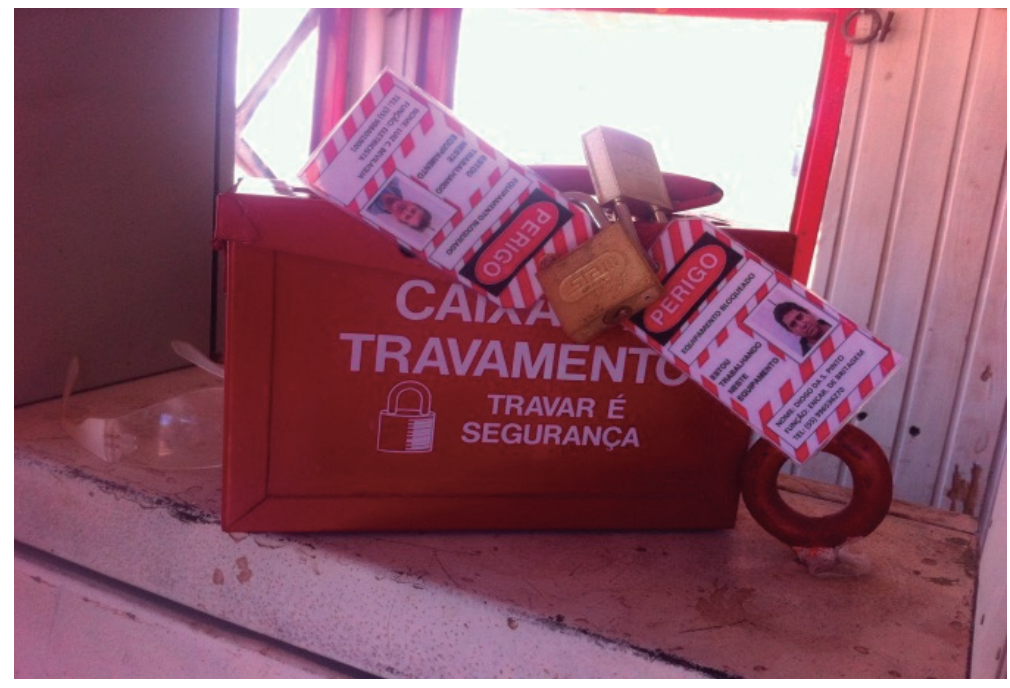

Fonte: Autor (2020).

Produção de Manual Técnico

Toda a máquina deve ter manual de instalação (quando aplicado); operação e manutenção em português (Brasil) de forma clara (fácil entendimento), didática, objetiva e atualizada; ter sinais ou avisos referentes à segurança realçados e permanecer disponíveis a todos os usuários nos locais de trabalho.

\section{CONSIDERAÇÕES FINAIS}

Considera-se a NR-12 extremamente importante para resguardar a saúde e a integridade física dos trabalhadores do segmento da mineração. Mesmo sendo obrigatória para empresas que empregam trabalhadores regidos pela CLT, verificou-se que os requisitos da NR-12 não foram suficientemente atendidos durante o estudo de caso realizado em uma unidade de produção mineral, localizada no município de Santa Maria, no Estado do Rio Grande do Sul, na região sul do Brasil.

Como requisitos inexistentes, pode-se apontar a ausência de rearme (reset) manual, proteções mecânicas móveis intertravadas, proteções mecânicas fixas, aterramento, chave seccionadora para Lock out - Tag out e laudo final de conformidade com a NR-12. 
Por fim, elaborou-se uma norma de adequação, que se mostrou eficaz ao reduzir o risco extremo e o risco muito alto para uma situação de risco aceitável durante as operações no britador primário de mandíbulas e da esteira transportadora. Além do alcance dos objetivos, a adequação do britador primário de mandíbulas às normas de segurança por parte do empreendedor, motivada pela avaliação de perigos e riscos, representam uma melhora significativa na proteção da integridade física dos operadores e colaboradores.

Os benefícios alcançados por meio da implementação dos dispositivos de segurança, conforme ABNT NBR 14153:2013 e NR-12, vão além dos citados anteriormente, uma vez que os colaboradores foram treinados e capacitados em todo o processo. O trabalho fornece subsídios para que empresas possam refletir sobre a relação custo benefício envolvida no cumprimento das exigências legais com fins de preservar a saúde e a integridade física dos colaboradores.

A realização da pesquisa proporciona a oportunidade de pôr em prática os conhecimentos adquiridos durante o curso de especialização em Engenharia de Segurança do Trabalho, oferecido pela Universidade Franciscana. Esse curso contribuiu para a formação e o aprofundamento dos conhecimentos adquiridos na área de prevenção de acidentes e doenças na operação e manutenção de máquinas e equipamentos.

\section{REFERÊNCIAS}

ADAMS, J.; THOMPSON, M. Taking account of societal concerns about risk: framing the problem. Sudbury: HSE Books, 2002. Disponível em: https://bit.ly/2SftHSq. Acesso em: 9 nov. 2020.

ASSOCIAÇÃO BRASILEIRA DE NORMAS TÉCNICAS. ABNT NBR 14153: segurança de máquinas: partes de sistemas de comando relacionados à segurança: princípios gerais para projeto. Rio de Janeiro: ABNT, 2013a.

ASSOCIAÇÃO BRASILEIRA DE NORMAS TÉCNICAS. ABNT NBR ISO 12100: segurança de máquinas: princípios gerais para projeto: apreciação e redução de riscos. Rio de Janeiro: ABNT, $2013 b$.

BRASIL. Ministério do Trabalho. Norma Regulamentadora $\mathbf{n}^{0} 01$. Disposições gerais e gerenciamento de riscos ocupacionais. Brasília, DF: Ministério do Trabalho, 1978d. Disponível em: https:// bit.ly/3ufNNdn. Acesso em: 2 set. 2020.

BRASIL. Ministério do Trabalho. Norma Regulamentadora nº 02. Inspeção prévia. Brasília, DF: Ministério do Trabalho, 1978b. Disponível em: https://bit.ly/3ugynpo. Acesso em: 15 set. 2020. 
BRASIL. Ministério do Trabalho. Norma Regulamentadora $\mathbf{n}^{0}$ 09. Programa de prevenção de riscos ambientais. Brasília, DF: Ministério do Trabalho, 1978e. Disponível em: https://bit.ly/3gWZPET. Acesso em: 18 set. 2020.

BRASIL. Ministério do Trabalho. Norma Regulamentadora $\mathbf{n}^{\mathbf{0}} \mathbf{1 0}$. Segurança em instalações e serviços em eletricidade. Brasília, DF: Ministério do Trabalho, 1978g. Disponível em: https://bit.ly/ 3tm2Y3K. Acesso em: 5 out. 2020.

BRASIL. Ministério do Trabalho. Norma Regulamentadora n 12. Segurança no trabalho em máquinas e equipamentos. Brasília, DF: Ministério do Trabalho, 1978f. Disponível em: https:/bit.ly/ 3ePXyIW. Acesso em: 2 nov. 2020.

BRASIL. Ministério do Trabalho. Norma Regulamentadora n 17. Ergonomia. Brasília, DF: Ministério do Trabalho, 1978f. Disponível em: https://bit.ly/3tm2ZVm. Acesso em: 2 nov. 2020.

BRASIL. Ministério do Trabalho. Norma Regulamentadora $\mathbf{n}^{\mathbf{0}}$ 22. Segurança e saúde ocupacional na mineração. Brasília, DF: Ministério do Trabalho, 1978a. Disponível em: https://bit.ly/2Rn3VLy. Acesso em: 5 nov. 2020.

BRASIL. Ministério do Trabalho. Norma Regulamentadora $\mathbf{n}^{0} 27$. Registro profissional do técnico de segurança do trabalho. Brasília, DF: Ministério do Trabalho, 1978c. Disponível em: https://bit.ly/ 2QIAEeD. Acesso em: 9 nov. 2020.

INSTITUTO BRASILEIRO DE MINERAÇÃO (org.). Informações sobre a economia mineral brasileira 2020: ano base 2019. Brasília, DF: IBRAN, 2020. Disponível em: file://C:/Users/14047/ Downloads/Economia-Mineral-Brasileira-IBRAM-2020.pdf. Acesso em: 10 dez. 2020.

PORTAL DA MINERAÇÃO. Quem somos. 2020. Disponível em: https://portaldamineracao.com.br/ o-portal/. Acesso em: 17 jan. 2021.

YIN, R. K. Estudo de caso: planejamento e métodos. Porto Alegre: Bookman, 2015. 